\title{
Características da sílica coloidal e seus efeitos em concretos refratários
}

\section{(Characteristics of colloidal silica and its effects on refractory castables)}

\author{
M.V.M.Magliano, V.C.Pandolfelli \\ Grupo de Engenharia de Microestrutura de Materiais - GEMM, Departamento de Engenharia de Materiais \\ Universidade Federal de S. Carlos, Rod. Washington Luiz, km 235, C.P. 676, S. Carlos, SP 13565-905 \\ vicpando@power.ufscar.br
}

\begin{abstract}
Resumo
A sílica coloidal se apresenta como um promissor substituto do cimento de aluminato de cálcio para utilização em concretos mulitizáveis. O uso deste ligante promove adequada resistência mecânica a verde, facilidade de secagem, inibe a formação de fases de baixo ponto de fusão, além de favorecer a formação de mulita in-situ. Entretanto, as propriedades finais do concreto dependem das características da solução coloidal utilizada. O objetivo deste trabalho é comparar as propriedades a verde e a quente de sistemas mulitizáveis ligados por sílica coloidal, variando suas características, tais como teor de sólidos, área superficial e tipo de estabilizante. Os resultados indicaram que sílicas coloidais com alta área superficial reduzem a trabalhabilidade dos concretos e diminuem as propriedades a quente devido ao acentuado trincamento durante a cura. A refratariedade dos sistemas é ainda comparada com concretos ligados por cimento de aluminato de cálcio e alumina hidratável, ressaltando a superioridade do ligante coloidal.
\end{abstract}

Palavras-chave: sílica coloidal, mulita, concreto refratário, ligantes a verde.

\begin{abstract}
The colloidal silica has been shown as a promising substitute for the aluminate cement as a binder for refractory castables. It can promote suitable mechanical strength for green bodies, reduce the explosion risk and does not develop phases with low melting point in the alumina systems. In addition, they can induce the in-situ mullite formation. Nevertheless, the final properties of the castable can also depend on the colloidal suspension characteristics such as, solid concentration, surface area and stabilizing agents. This paper aims to compare the green and high temperature properties of castables using different types of colloidal silicas. The results showed that colloidal silica containing a high surface area builds up internal tensions and cracks during the drying process, which deteriorate the hot mechanical properties of the castables. Besides that, they also reduce the workability and the free flow of the system. The results presented were also compared with the refractoriness of others binding systems such as aluminate cement and reactive alumina on colloidal silica containing castables.
\end{abstract}

Keywords: colloidal system, mullite, refractory castable, binding system.

\section{INTRODUÇÃO}

O avanço tecnológico de concretos refratários para aplicações a altas temperaturas está intimamente relacionado ao desenvolvimento de ligantes que sejam mais facilmente aplicáveis e que resultem em superior desempenho durante o uso. Atualmente, com a forte presença da nanotecnologia em quase todos os campos de pesquisa, têm sido desenvolvidos ligantes nano estruturados, entre os quais se destaca a sílica coloidal. Trabalhos comprovando a eficácia deste ligante têm sido realizados e suas propriedades são comumente comparadas com as dos concretos contendo cimentos aluminosos (CAC) [1-3]. A sílica coloidal apresenta especial potencial para utilização como ligante em concretos contendo $\mathrm{Al}_{2} \mathrm{O}_{3} \mathrm{e} \mathrm{SiO}_{2}$, pois pode facilitar a etapa de secagem, diminuir a porosidade após queima e gerar mulita in-situ, melhorando as propriedades a quente [1-5]. Entretanto, sua utilização requer conhecimento adequado das características e reações de pega, especialmente a temperatura ambiente.
A pega nesses sistemas ocorre por meio da gelificação da solução, onde as nanopartículas de sílica reagem formando ligações primárias fortes que as mantem unidas, gerando um sólido de estrutura nanoporosa. A gelificação é decorrente da formação da ligação silanol ( $\mathrm{Si}-\mathrm{O}-\mathrm{Si}$ ) na interface entre as partículas (equação $\mathrm{A}$ ), onde um pescoço é formado por dissolução e precipitação, devido a diferença de raio de curvatura [6].

$$
\mathrm{Si}-\mathrm{O}-\mathrm{H}^{\alpha+}+{ }^{\alpha-} \mathrm{O}-\mathrm{H}-\mathrm{Si}=\mathrm{Si}-\mathrm{O}-\mathrm{Si}+\mathrm{H}_{2} \mathrm{O}
$$

O processo tem inicio com a desestabilização da suspensão, que permite a aproximação das partículas. Durante a gelificação, uma partícula que se aproxime de duas outras já unidas tende a colidir lateralmente em uma das extremidades (menor repulsividade), formando uma cadeia preferencialmente linear [6]. Como resultado, uma estrutura em forma de "corrente ramificada" contendo nanoporos (Fig. 1) é gerada, ocupando todo o espaço disponível da 


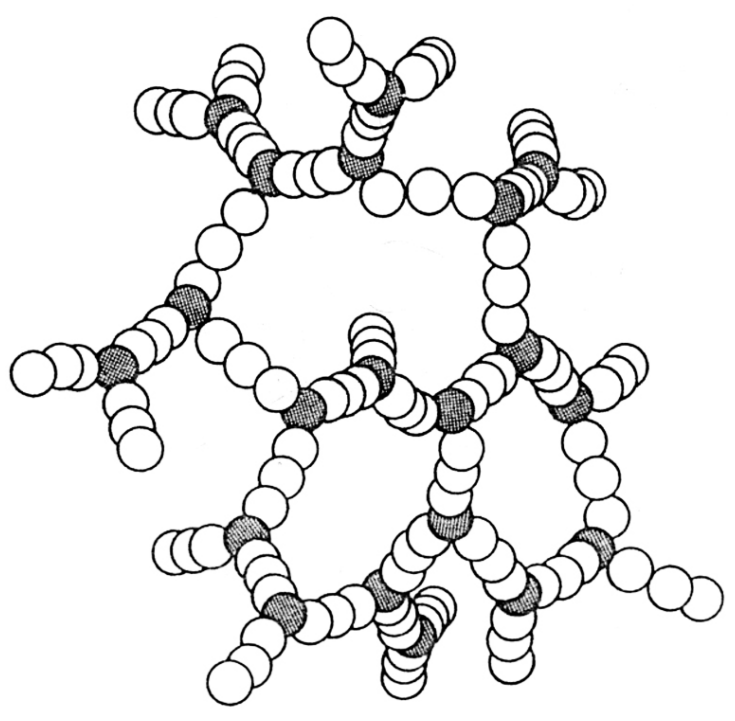

Figura 1: Estrutura nanoporosa do gel de sílica [6].

[Figure 1: Nanoporous sílica gel structure [6].]

solução. Conforme o gel seca, a estrutura retrai gerando tensões internas e trincas. Quanto maior a área superficial das partículas e a concentração de sólidos, maiores serão as tensões e possíveis trincas geradas no precipitado.

Sílicas coloidais são comumente estabilizadas por repulsão eletrostática por meio do controle do pH [6-8]. Em pHs acima de 9 a superfície das partículas apresenta alta densidade de carga negativa impossibilitando a aproximação e o contato entre elas. Portanto, para que a reação se processe é necessário diminuir a carga superficial. Isto pode ocorrer por 3 métodos distintos: redução do $\mathrm{pH}$, secagem da água da suspensão ou adição de gelificante [6-8]. Para aplicação em concretos os dois últimos métodos são utilizados, pois a alteração do pH da composição modifica a dispersão e o empacotamento das partículas.

Sais solúveis são comumente utilizados como gelificante, pois ao serem adicionados liberam íons (cátions e ânions). Os cátions são atraídos para a superfície negativa das partículas, neutralizando parte da carga e diminuindo a repulsividade. $\mathrm{Na}$ gelificação por secagem as partículas se agrupam sem auxílio de agentes gelificantes. Durante a secagem a concentração da suspensão aumenta devido a evaporação da água, forçando as partículas a se aproximarem pela restrição de espaço físico (Fig. 2). Na prática é comum a utilização simultânea de ambos os processos.

A estabilidade e a força de ligação das sílicas coloidais são fortemente influenciadas pela reatividade da solução. Suspensões com alta área superficial apresentam curto tempo para formação do gel (tempo de gel) e aumentam o poder ligante da estrutura. Entretanto, potencializam a retração durante a secagem gerando tensões internas que podem causar trincas. Dois fatores são responsáveis pela reatividade das soluções: a) tamanho médio de partícula, sendo este o fator principal, e b) a concentração de sólidos. Suspensões de menor tamanho de partícula e maior teor de sólidos são as mais reativas.
Desta forma, fatores como a reologia e as propriedades dos concretos podem ser significativamente afetados pelo tipo de sílica coloidal utilizada. Assim, esse trabalho tem como objetivo determinar de que maneira as características desses ligantes afetam o comportamento reológico, as propriedades e a formação de mulita em concretos aluminosilicosos. Os sistemas nano-ligados são ainda comparados em termos de refratariedade e sinterabilidade com sistemas mulitizáveis tradicionais, que utilizam CAC e alumina hidratável como ligante.
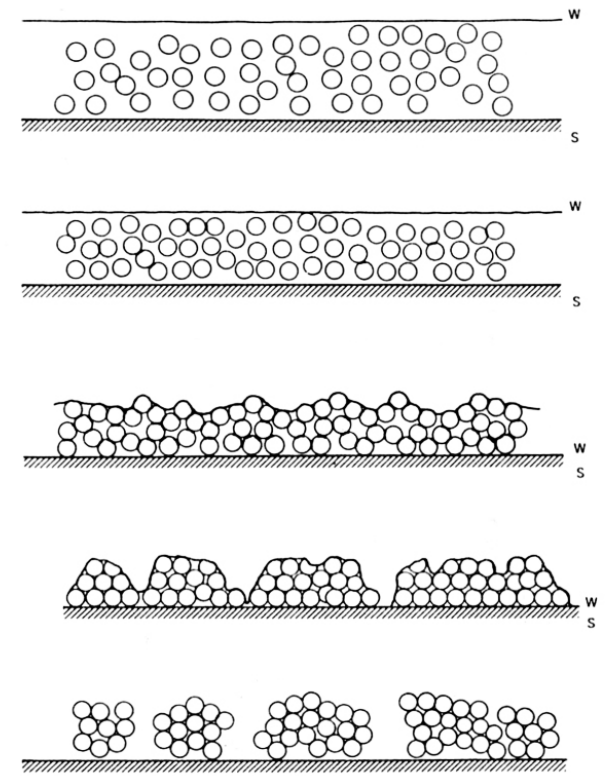

Figura 2: Processo de gelificação por secagem [6]. [Figure 2: Gelification process by drying [6].]

\section{MATERIAIS E MÉTODOS}

\section{Formulação dos concretos e processamento}

As composições utilizadas neste trabalho foram formuladas utilizando o software PSDesigner desenvolvido no GEMM. Todas as composições continham em sua matriz a proporção de $24 \%$ de $\mathrm{SiO}_{2}$ e $76 \%$ de $\mathrm{Al}_{2} \mathrm{O}_{3}$, sendo a quantidade de agregados próxima a $70 \%$. O coeficiente de empacotamento utilizado foi o de Andreasen com q $=0,21$. A Tabela I mostra as matérias primas utilizadas nesse trabalho.

Com o intuito de testar o efeito da reatividade da sílica sobre as propriedades do concreto foram utilizadas diferentes fontes de sílica como mostra a Tabela II.

Os concretos foram processados em um reômetro [7]. A Tabela III apresenta os sistemas estudados e as quantidades de água e de ligante utilizados. Nos concretos contendo sílica coloidal primeiramente foi adicionada a água com o reômetro em baixa rotação $(20 \mathrm{rpm})$. A quantidade desta variou de acordo com a concentração de cada tipo de solução, visando a obtenção de $4,8 \%$ de água total no sistema. Posteriormente, a rotação foi aumentada para $55 \mathrm{rpm}$ e o ligante coloidal 
Tabela I - Matérias primas utilizadas no trabalho*. [Table I - Raw materials used in this work.]

\begin{tabular}{cc}
\hline Material & Especificações \\
\hline Alumina eletrofundida marrom & $4 / 10,8 / 20,20 / 40$, TP40 \\
Tlumina calcinada & A1000SG, CL370 C \\
Microssílica & MS971U \\
Cimento de aluminato de & Secar 71 \\
cálcio & Aphabond 300 \\
Alumina hidratável & Eka \\
Sílica coloidal &
\end{tabular}

"Fornecedores: alumina tabular, alumina calcinada e alumina hidratável: Almatis (EUA); alumina eltrofundida marrom: Elfusa S.A; cimento de aluminato de cálcio: Kerneos; sílica coloidal: Eka.

adicionado. O tempo de mistura foi próximo a $300 \mathrm{~s}$ para todos os sistemas, exceto para o $\mathrm{AB}+\mathrm{MS}$ (500 s). Os aditivos dispersantes foram adicionados e previamente misturados no pó ainda seco, não sendo utilizados agentes gelificantes. A composição contendo CAC foi curada a $50{ }^{\circ} \mathrm{C}$ por $12 \mathrm{~h}$ em ambiente saturado por vapor de água. As composições contendo sílica coloidal (SC), e alumina hidratável (AB) foram curadas a $110^{\circ} \mathrm{C}$ em ambiente insaturado por $12 \mathrm{~h}$.

\section{Fluidez de mistura}

A medida da fluidez foi efetuada colocando-se a massa logo após a mistura em um molde sobre uma mesa vibratória. O molde consiste em um tronco de cone vazado nas duas extremidades (medidas: diâmetro superior 100 $\mathrm{mm}$, diâmetro inferior $70 \mathrm{~mm}$ e altura $65 \mathrm{~mm}$ ). Com a retirada do molde a massa flui livremente e a medida de fluidez é efetuada. A fluidez livre (FF) é avaliada pelo espalhamento espontâneo do concreto após $30 \mathrm{~s}$ da retirada do molde. A fluidez vibrada (VF) é avaliada pelo espalhamento sob vibração do concreto após $60 \mathrm{~s}$ da retirada do molde.

Tabela II - Especificações das soluções coloidais utilizadas no trabalho.

[Table II - Colloidal sílica used in this work.]

\begin{tabular}{cccccc}
\hline Classificação & $\begin{array}{c}\text { Diâmetro } \\
(\mathrm{nm})\end{array}$ & $\begin{array}{c}\text { Concentração } \\
(\%)\end{array}$ & $\begin{array}{c}\text { Área superficial } \\
\left(\mathrm{m}^{2} / \mathrm{g}\right)\end{array}$ & Carga superficial & Aditivo estabilizante \\
\hline $14 / 30$ & 14 & 30 & 220 & negativa & $\mathrm{Na}$ \\
$14 / 40$ & 14 & 40 & 250 & negativa & $\mathrm{Na}$ \\
$8 / 30$ & 8 & 30 & 300 & negativa & $\mathrm{Na}$ \\
$50 / 80$ & 80 & 50 & - & negativa & $\mathrm{Na}$ \\
$15 / 750$ & 3 & 15 & 750 & negativa & $\mathrm{Na}$ \\
$40 \mathrm{NH}_{3}$ & 80 & 40 & - & negativa & $\mathrm{NH}_{3}$ \\
Cat80 & 80 & 50 & - & positiva & $\mathrm{Al}_{2} \mathrm{O}_{3}$ \\
\hline
\end{tabular}

Tabela III - Sistemas ligantes utilizados neste trabalho*. [Table III - Binder systems used in this work.]

\begin{tabular}{ccccccc}
\hline Composição & SC (\%) & MS (\%) & $\begin{array}{c}\text { AB ou CAC } \\
(\%)\end{array}$ & Quantidade de aditivo & $\begin{array}{c}\text { água } \\
\text { adicional } \\
(\%)\end{array}$ & $\begin{array}{c}\text { Total de } \\
\text { água (\%) }\end{array}$ \\
\hline${\text { CAC }+\mathrm{MS}^{*}}^{*}$ & - & 7,2 & 1,5 & FS20 0,13\% & 5 & 5 \\
$\mathrm{AB}^{*}+\mathrm{MS}$ & 0 & 7,2 & 3 & Ac. Cítrico 0,20\% & 5,25 & 5,25 \\
$8 / 30$ & 5 & 5,2 & 0 & Ac. Cítrico 0,06\% & 1,30 & 4,8 \\
$14 / 40$ & 5 & 5,2 & 0 & Ac. Cítrico 0,06\% & 1,80 & 4,8 \\
$50 / 80$ & 5 & 5,2 & 0 & Ac. Cítrico 0,06\% & 2,30 & 4,8 \\
CAT 80 & 5 & 5,2 & 0 & Ac. Cítrico 0,06\% & 0,7 & 4,8 \\
$15 / 750$ & 5 & 5,2 & 0 & Ac. Cítrico 0,06\% & 1,8 & 4,8 \\
$40 \mathrm{NH}$ & 5 & 5,2 & 0 & Ac. Cítrico 0,06\% & 1,3 & 4,8 \\
$14 / 30$ & 5 & 5,2 & 0 & & & \\
\hline
\end{tabular}




\section{Resistência mecânica e porosidade}

Para a medida da resistência mecânica foi utilizada uma maquina de ensaio universal MTS 810. O ensaio a verde foi realizado por compressão diametral (ASTM C 496-90) em corpos de prova cilíndricos $(\mathrm{h}=\mathrm{d}=40 \mathrm{~mm}) \log$ o após a cura. Quatro amostras foram utilizadas por composição. A resistência após queima foi inferida pela comparação entre os valores dos módulos elásticos das composições. A porosidade aparente foi medida pelo método de imersão de Arquimedes, utilizando água como líquido de acordo com a norma ASTM C830-88.

\section{Refratariedade sobre carga e sinterabilidade assistida}

Ambos os ensaios foram realizados no equipamento Netzsch RUL 421E em corpos de prova cilíndricos (dimensões $\mathrm{h}=\mathrm{d}=50 \mathrm{~mm}$ ) contendo um furo central de $12,5 \mathrm{~mm}$. No ensaio de refratariedade sobre carga foram utilizadas amostras pré-queimadas a $1500^{\circ} \mathrm{C}$ por $10 \mathrm{~h}$. A taxa de aquecimento foi de $5^{\circ} \mathrm{C} / \mathrm{min}$, até $1600^{\circ} \mathrm{C}$, sendo aplicada uma carga compressiva de 0,2 $\mathrm{MPa}$ sobre os corpos. No ensaio de sinterabilidade assistida foram utilizadas amostras pré-calcinadas a $600{ }^{\circ} \mathrm{C}$ por $2 \mathrm{~h}$. A taxa de aquecimento do ensaio foi de $5{ }^{\circ} \mathrm{C} / \mathrm{min}$ até $1500{ }^{\circ} \mathrm{C}$ (patamar $5 \mathrm{~h}$ ), sob uma carga compressiva de $0,02 \mathrm{MPa}$.

\section{Módulo de ruptura a quente}

$\mathrm{O}$ ensaio de resistência mecânica a quente foi realizado a $1450{ }^{\circ} \mathrm{C}$ em amostras pré-queimadas a $1500{ }^{\circ} \mathrm{C}$ por $10 \mathrm{~h}$. Barras de $150 \mathrm{~mm}$ x $25 \mathrm{~mm}$ x $25 \mathrm{~mm}$ foram utilizadas em um equipamento de flexão 3 pontos modelo HBST (High Bending Strength Tester) 422, Netzsch, de acordo com a norma ASTM C 583-8. A taxa de aplicação de carga foi de $12 \mathrm{~N} / \mathrm{s}$ e a distância entre os apoios $125 \mathrm{~mm}$.

\section{Módulo elástico}

Foram realizadas as medidas do módulo elástico (E) das composições com o intuito de verificar a rigidez das amostras após a queima e inferir assim, as diferenças de resistência mecânica a frio entre os sistemas. A medida de E foi realizada utilizando-se o método de ressonância de barras (ASTM C 1198-91). As freqüências de ressonância e o cálculo do módulo foram efetuadas utilizando-se o equipamento Escaneslatic, desenvolvido em parceria com a empresa ATCP do Brasil.

\section{RESULTADOS E DISCUSSÃO}

\section{Trabalhabilidade e fluidez}

Os resultados de fluidez (Tabela IV) mostram que os maiores valores foram obtidos para os sistemas que utilizaram sílicas coloidais com superior tamanho de partículas $(50 / 80$ e $40 \mathrm{NH})$, e que, entre as soluções de mesmo diâmetro médio, os maiores valores de fluidez foram apresentados para aquelas com menores concentrações. Este resultado indica que a fluidez do sistema diminui com o aumento da reatividade da sílica coloidal.

As composições 15/750 e CAT80 não apresentaram trabalhabilidade mínima de moldagem. A primeira, devido ao pequeno tamanho de partícula $(3 \mathrm{~nm})$, reduz significativamente o tempo de gelificação. Nesse sistema a pega ocorreu rapidamente e a fluidez de mistura resultou valor próximo a zero, impossibilitando a moldagem de amostras. O sistema CAT 80 também não pode ser moldado, pois suas partículas possuem carga superficial positiva, levando-o a atuar como um coagulante da microssilica presente na matriz, que possui carga superficial negativa [9]. Durante a mistura este sistema apresentou alto grau de coagulação que impossibilitou a moldagem e até mesmo a virada do concreto.

\section{Resistência mecânica e porosidade a verde}

Os resultados de resistência mecânica a verde (Fig. 3) podem ser analisados considerando-se dois fatores concorrentes: o poder de ligação do gel e os defeitos gerados na estrutura durante a secagem.

Soluções de alta reatividade (menor tamanho de partícula e maior concentração) formam géis mais resistentes, o que contribui para o aumento da resistência mecânica. Porém,

Tabela IV - Resultado de fluidez das composições que utilizaram sílica coloidal.

[Table IV - Flow results for the compositions containing colloidal silica.]

\begin{tabular}{cccccc}
\hline Composição & Diâmetro $(\mathrm{nm})$ & Concentração $(\%)$ & Total de água $^{*}(\%)$ & $\mathrm{FF}^{* *}(\%)$ & $\mathrm{VF}^{* *}(\%)$ \\
\hline $8 / 30$ & 8 & 30 & 4,8 & 35 & 95 \\
$14 / 40$ & 14 & 40 & 4,8 & 38 & 110 \\
$50 / 80$ & 80 & 50 & 4,8 & 73 & 126 \\
$15 / 750$ & 3 & 18 & 4,8 & 0 & 0 \\
CAT80 & 80 & 50 & 4,8 & 0 & 0 \\
$40 \mathrm{NH}$ & 80 & 40 & 4,8 & 73 & 133 \\
$14 / 30$ & 14 & 30 & 4,8 & 61 & 146 \\
\hline
\end{tabular}

${ }^{*}$ Corresponde à água contida na solução coloidal mais a água previamente adicionada $;{ }^{* *} \mathrm{FF} \%=$ fluidez livre, VF\% $=$ fluidez sob vibração 


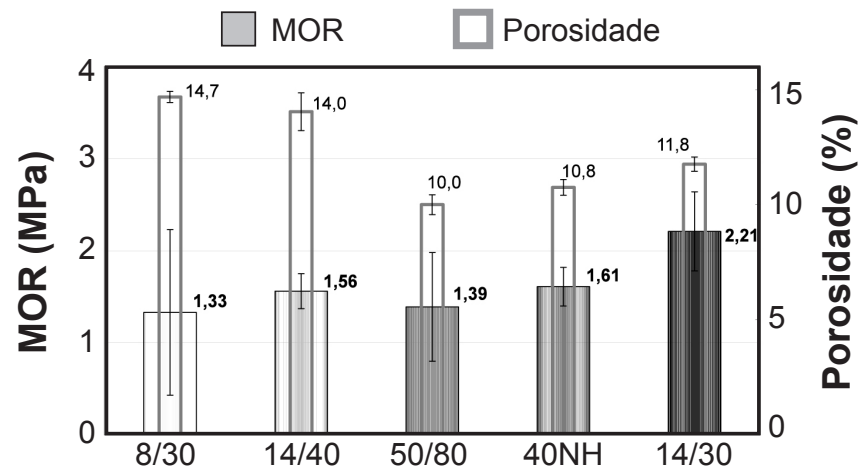

Figura 3: Resistência mecânica e porosidade a verde após cura por $12 \mathrm{~h}$ a $110^{\circ} \mathrm{C}$.

[Figure 3: Green mechanical strength and porosity after curing for 12 h at $\left.110^{\circ} \mathrm{C}.\right]$

a alta reatividade gera maior trincamento da estrutura, reduzindo o módulo de ruptura e aumentando a porosidade [6]. O balanço entre esses fatores é o responsável pelo desenvolvimento da resistência mecânica a verde nos sistemas. A análise das porosidades a verde mostra que os sistemas contendo ligantes mais reativos resultaram maiores porosidades devido ao maior microtrincamento nos corpos e à formação de géis de estrutura mais aberta [6]. O sistema 14/30 apresentou o melhor balanço entre força de ligação das partículas e as tensões internas, resultando superior resistência mecânica. $\mathrm{O}$ alto valor da porosidade no sistema $8 / 30$ foi devido a alta reatividade do mesmo $\left(D_{50}=8 \mathrm{~nm}\right)$ que gerou um número acentuado de defeitos durante a secagem, ocasionando aumento da porosidade e comprometendo a reprodutibilidade dos concretos. O grande desvio nos valores de resistência mecânica se deve aos diferentes comprimentos de trinca nas amostras. No entanto, embora estas trincas tenham causado um aumento na porosidade, resultaram em um pequeno desvio padrão nesta propriedade.

\section{Módulo elástico e porosidade após queima}

O grau de dano na estrutura das amostras e a resistência mecânica após a queima foram inferidos a partir do valor

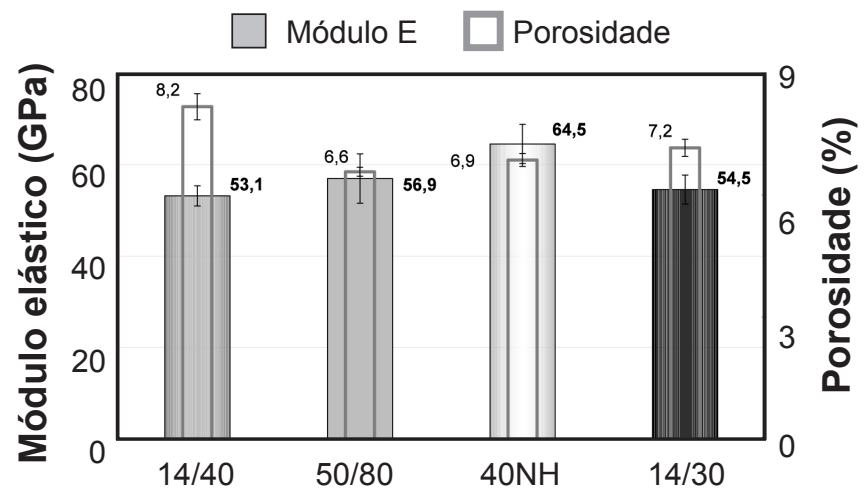

Figura 4: Módulo elástico e porosidade após queima a $1500{ }^{\circ} \mathrm{C}$ por $10 \mathrm{~h}$.

[Figure 4: Elastic modulus and porosity after sintering at $1500{ }^{\circ} \mathrm{C}$ for $10 \mathrm{~h}$. do módulo elástico. A Fig. 4 apresenta os resultados deste ensaio e as respectivas porosidades após queima.

Os sistemas que utilizaram soluções menos reativas resultaram maiores valores de $\mathrm{E}$ e menores porosidades. A solução $40 \mathrm{NH}\left(\mathrm{D}_{50}=80 \mathrm{~nm}\right.$ e concentração $=40 \%$ p) de menor reatividade apresentou o maior valor de E, seguido do sistema $50 / 80\left(\mathrm{D}_{50}=80 \mathrm{~nm}\right.$ e concentração $\left.=50 \% \mathrm{p}\right)$, sendo este o segundo menos reativo. Ambos apresentaram porosidades inferiores aos demais. Os menores valores do módulo elástico foram obtidos para os sistemas 14/30 e 14/40, ambos possuindo $D_{50}=14 \mathrm{~nm}$. Estes resultaram porosidades superiores aos sistemas menos reativos. O sistema 8/30, devido a sua alta reatividade, não pode ter seu módulo elástico avaliado devido ao trincamento acentuado das amostras durante a secagem.

\section{Ensaios a quente}

Os resultados de resistência mecânica a quente (HMOR) se encontram na Fig. 5. Os valores apresentados mostraramse significativamente distintos. Neste ensaio, o efeito do trincamento ocasionado pela alta reatividade dos ligantes é potencializado.

Os dois sistemas que utilizaram as sílicas menos reativas (40NH e 50/80) resultaram nos maiores valores. O sistema $8 / 30$, de maior reatividade, apresentou módulo de ruptura inferior aos demais, comprovando que o trincamento gerado durante a cura comprometeu as propriedades a quente.

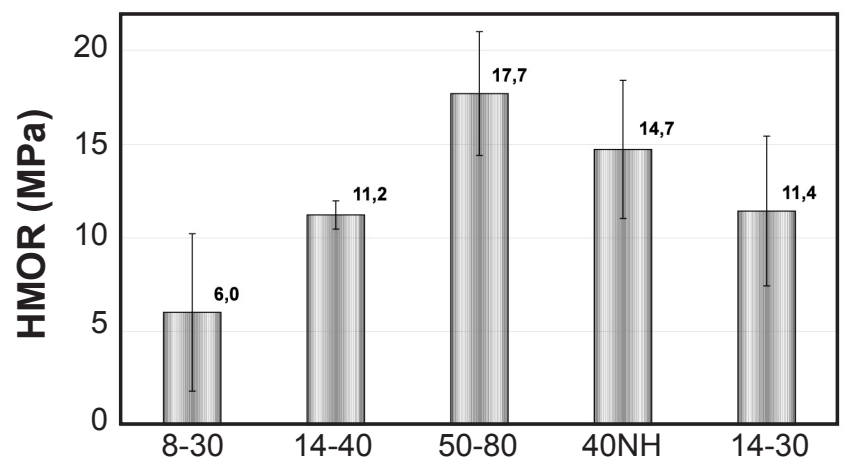

Figura 5: Módulo de ruptura a $1450{ }^{\circ} \mathrm{C}$ para corpos pré-queimados a $1500{ }^{\circ} \mathrm{C}$ por $10 \mathrm{~h}$.

[Figure 5: Hot mechanical strength at $1450^{\circ} \mathrm{C}$ for samples sintered at $1500{ }^{\circ} \mathrm{C}$ for $\left.10 \mathrm{~h}.\right]$

Com o intuito de averiguar a refratariedade e a mulitização dos sistemas o ensaio de refratariedade sob carga foi realizado. A Fig. 6 apresenta o gráfico de deformação em função da temperatura, comparando os sistemas ligados por agentes coloidais com outras composições potencialmente mulitizadoras utilizando ligantes tradicionais, alumina hidratável e CAC. Todos os sistemas ligados por sílicas coloidais apresentaram deformação inferior aos ligantes tradicionais, apesar de algumas composições apresentarem defeitos gerados pela secagem. Esses defeitos afetam muito 
mais os valores dos ensaios onde a ruptura é obtida por flexão (MOR e HMOR), que os ensaios onde a solicitação mecânica é por compressão. Alem disso, as sílicas coloidais possuem nanopartículas que diminuem a temperatura de formação da mulita, resultando em maior teor dessa fase e menor quantidade de fase líquida residual, aumentando assim a refratariedade do sistema [8-10].

A Fig. 6 mostra ainda que dentre as composições coloidais, as de maior reatividade 8/30 e 14/40 apresentaram maior refratariedade, enfatizando que o menor tamanho de suas partículas favorece a mulitização.

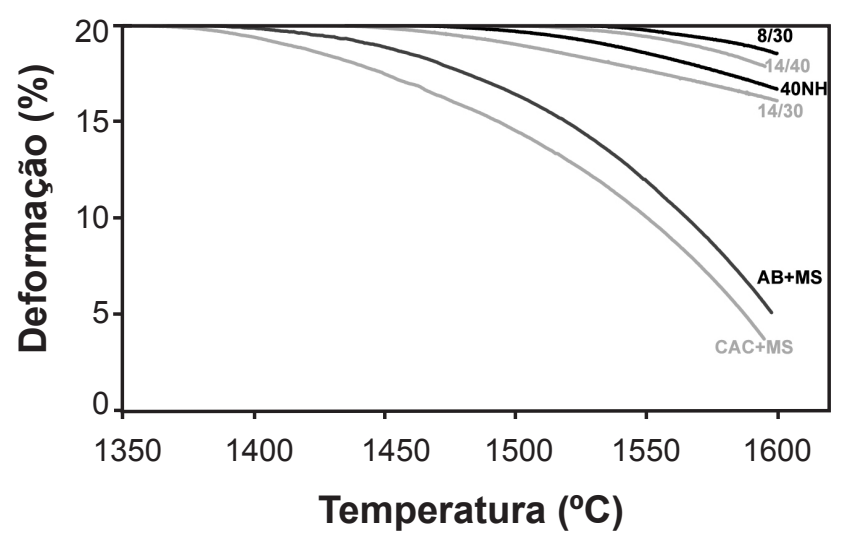

Figura 6: Refratariedade sob carga.

[Figure 6: Refractoriness under load.]

O sistema 50/80, de menor reatividade, não foi apresentado no gráfico, uma vez que durante o ensaio, ao atingir temperaturas acima de $1500^{\circ} \mathrm{C}$, o sistema apresentou expansão típica de mulitização, indicando que devido ao maior tamanho de suas partículas, a mulitização neste sistema ocorre tardiamente.

Para averiguar de forma mais precisa o grau de mulitização e sinterização dos sistemas, realizou-se o ensaio de sinterabilidade sob carga (Fig. 7). Neste ensaio, as sílicas coloidais de maior reatividade $(8 / 30)$, a de menor reatividade $(50 / 80)$ e a comercialmente utilizadas em refratários (14/40), foram testadas e comparadas com os sistemas ligados por alumina hidratável e CAC. A formação de mulita é acompanhada de uma expansão da matriz, já que a densidade dessa fase é menor que da alumina, principal componente destes refratários. A Fig. 7 mostra que todos os sistemas apresentaram expansão típica de mulitização durante o ensaio, na faixa de temperatura entre 1200 e $1500{ }^{\circ} \mathrm{C}$. Importante notar que uma vez atingido o patamar de temperatura, a expansão cessa, indicando que a reação de mulitização foi interrompida pelo término do aquecimento, enfatizando a necessidade do aumento da temperatura para prosseguimento da reação de mulitização. A reação de mulitização inicia-se com a interdifusão de íons alumínio e silício nas interfaces de partículas de $\mathrm{Al}_{2} \mathrm{O}_{3}$ e $\mathrm{SiO}_{2}$ [8-11]. Preferencialmente, os íons provenientes da alumina se difundem para o interior da sílica destruindo sua estrutura. Dessa forma um líquido meta-estável de alta viscosidade é gerado, acelerando a difusão destes óxidos. Conforme a temperatura é aumentada, mais íons alumínio são dissolvidos no líquido e o mesmo se enriquece em alumina, formando a ligação $\mathrm{Si}-\mathrm{O}-\mathrm{Al}$. A nucleação de mulita se estabelece quando as quantidades de sílica e alumina alcançam a proporção estequiométrica da fase. Conforme a temperatura é elevada, mais íons alumínio são dissolvidos no líquido silicoso e consequentemente mais mulita é precipitada na estrutura. Uma vez atingido o patamar de temperatura, a dissolução da $\mathrm{Al}_{2} \mathrm{O}_{3}$ cessa e o líquido restante que não precipitou em mulita se mantém na estrutura como fase vítrea residual.

Desta forma, quanto mais baixa a temperatura de inicio de mulitização, maior o teor de mulita final no sistema [8-11]. Partículas nanométricas, por serem mais reativas, antecipam a reação e conseqüentemente geram maior teor da fase na estrutura. O sistema $8 / 30$, devido a sua alta reatividade, gera uma retração de sinterização acentuada.

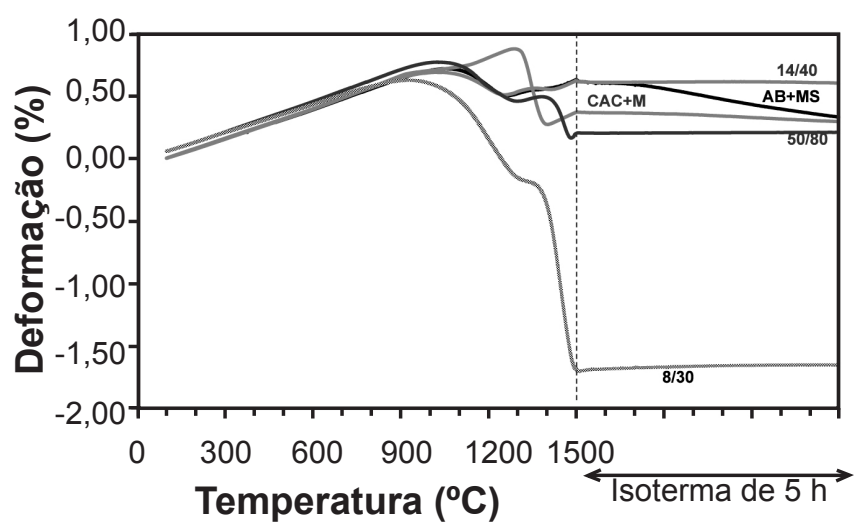

Figura 7: Sinterabilidade sob uma carga de 0,02 MPa para amostras préviamente calcinadas a $600{ }^{\circ} \mathrm{C}$.

[Figure 7: Sinterability under load (0.02 MPa) for samples previously calcinated at $600{ }^{\circ} \mathrm{C}$.]

\section{CONCLUSÃO}

Os resultados confirmam que a reatividade das sílicas coloidais dependem primeiramente do tamanho médio das partículas e em segundo lugar da concentração de sólidos. A reatividade das soluções coloidais são determinantes nas propriedades dos concretos. Suspensões muito reativas dificultam a trabalhabilidade, reduzem a fluidez e deterioram as propriedades mecânicas a quente e a frio, pois geram trincamento acentuado durante a secagem. Por outro lado, a alta reatividade aumenta a refratariedade do sistema pela formação de maior teor de mulita na estrutura. Suspensões de menor reatividade otimizam a trabalhabilidade, a fluidez e as propriedades mecânicas. Entretanto, diminuem a mulitização e a refratariedade dos concretos. Sílicas com tamanho de partícula menores que $14 \mathrm{~nm}(15 / 750$ e 8/30) não são indicadas para uso isolado em concretos devido a sua alta reatividade. Os ligantes coloidais em geral se mostraram mais eficazes que os tradicionais CAC e alumina hidratável em termos de mulitização e refratariedade, sendo mais indicado que 
estes para uso em concretos sílico-aluminosos.

\section{AGRADECIMENTOS}

Ao CNPQ pela ajuda financeira e à empresa Eka pelo fornecimento das amostras.

\section{REFERÊNCIAS}

[1] M. R. Ismael, A. O. Valenzuela, L. A. Polito, V. C. Pandolfelli, Propriedades termo-mecânicas de concretos refratários ligados por sílica coloidal, Cerâmica 53, 327 (2007) 314-318.

[2] M. R. Ismael, R. Salomão, L. A. Polito, V. C. Pandolfelli, Agentes ligantes para concretos refratários: sílica coloidal e alumina hidratável, Cerâmica 53, 326 (2007) 142-146.

[3] C. Parr, C. Wohrmeyer, The advantages of calcium aluminate cement as a castable bonding system, Lafarge Aluminates Paris, França.

[4] H. R. Rezaie, W. M. Rainforth, W. E. Lee, Mullite evolution in ceramics derived from kaolinite, kaolinite with added $\alpha$-alumina, and sol-gel precursor, Brit. Ceram. Trans.
96, 5 (1997) 181-187.

[5] J. A. Pask, X. W. Zhang, A. P. Tomasia, Effect of solgel mixing on mullite microstructure and phase equilibria in the $\alpha-\mathrm{Al}_{2} \mathrm{O}_{3}-\mathrm{SiO}_{2}$ system, J. Am. Ceram. Soc. 70, 10 (1997) 704-707.

[6] K. R. Iler, The chemistry of silica, John Wiley and Sons, Nova York (1979) 312-439.

[7] R. G. Pileggi, V. C. Pandolfelli, Reologia e distribuição granulométrica de concretos refratários bombeáveis, Cerâmica 48, 305 (2002) 11-16.

[8] M. Schneider, K. Okada, J. A. Pask, Mullite and mullite ceramics, John Wiley and Sons, Nova York, EUA (1994) 83145.

[9] I. A. Aksay, J. A. Pask, Stable and metastable equilibria in the system $\mathrm{SiO}_{2}-\mathrm{Al}_{2} \mathrm{O}_{3}$, J. Am. Ceram. Soc. 58, 11-12 (1975) 507-512.

[10] S. H. Risbud, J. A. Pask, $\mathrm{SiO}_{2}-\mathrm{Al}_{2} \mathrm{O}_{3}$ metastable phase equilibrium diagram without mulite, J. Mater. Sci. 13 (1978) 2449-2454.

[11] M. V. Gerotto, Concretos refratários aluminosos com matrizes mulíticas pela adição de microssílica caulim ou metacaulim, Diss. Mestrado, UFSCar, S. Carlos, SP (2000). (Rec. 12/04/08, Ac. 11/07/08) 